\title{
Physicochemical and mineralogical characterization of Moroccan bentonite of Trebia and its use in ceramic technology
}

\author{
Azzeddine Er-ramly*, Abdelali Ider \\ Laboratory Process of Valorization of the Natural Resources, Materials \& Environment, Department of Applied Chemistry \& Environment \\ Faculty of Sciences and Technologies Settat BP 577, University Hassan $1^{\text {st }}$ Morocco
}

Email address:

a.erramly@yahoo.fr(A. Er-ramly), a.erramly@gmail.com (A. Er-ramly), Abdeali_ider@yahoo.fr (A. Ider)

\section{To cite this article:}

Azzeddine Er-ramly, Abdelali Ider. Physicochemical and Mineralogical Characterization of Moroccan Bentonite of Trebia and Its Use in Ceramic Technology. American Journal of Physical Chemistry. Vol. 3, No. 6, 2014, pp. 96-101. doi: 10.11648/j.ajpc.20140306.12

\begin{abstract}
This study concerns the results of Physicochemical and mineralogical characterization of a white bentonite of Trebia located in Nador region in Morocco and its use in the ceramics industry. Several techniques were used; in particular X-ray diffraction (XRD), scanning electron microscopy coupled with EDX microanalysis (SEM-EDX), differential thermal and gravimetric analyses (DTA-TGA) and finally infrared Fourier transform (FTIR) and X-ray fluorescence (XRF). The first objective of this work is to look for the usability of bentonite of Trebia in ceramic technology. The second objective was to develop gels of oxides of high purity from these clays. We can say that the white bentonite of Trebia has the same characteristics of clays used in the ceramics industry (medium heat loss, low shrinkage, good flexural strength and good behavior in plasticity), this white bentonite of Trebia adding $0,42 \%$ sodium carbonate is sufficient to have a good deflocculation and the viscosity is minimum corresponds to the stability of the slip, in his introduction to a formula of slip was successful with a rate of 10 to $14 \%$. The SEM-EDX, X-ray, chemical analysis and Infrared spectroscopy demonstrated and allowed us to identify the different minerals that make up the white clay, compared with the available data, we identified Montmorillonite, feldspath and quartz as bentonite of Trebia, other minerals present as impurities major are magnetit and iron oxide. These results show the important features to justify its use in the ceramic industry.
\end{abstract}

Keywords: Bentonite, Ceramic, DTA, FX, XRD, FTIR

\section{Introduction}

Today, the use of clays, including those that are rich in $\mathrm{SiO}_{2}$ and $\mathrm{Al}_{2} \mathrm{O}_{3}$, is experiencing a boom in new construction, ceramics and crafts, pharmaceuticals foundry and pottery. Aluminosilicate bricks are used in the coating of blast furnaces, refining furnaces and kilns in many laboratory ovens. The ceramic materials have a wide range of application include dental prostheses based on silica and alumina.

The bentonite of Trebia that is the subject of this work is known as "Nador white Clay" consisting essentially of Montmorillonite, feldspath and quartz, in its natural state. Most bentonite of Trebia deposits in this region of north Morocco are heterogeneous and are composed of some smectites mixed with kaolinite and other impurities [1]. In the liquid state, mud bentonite of Trebia is defined as a water-bentonite of Trebia suspension, the origin of the use of sludge is probably the drilling of oil wells [2]. It allows, due to its rheological properties in order to respond to numerous requests for drilling, such as the stability of the structure (the impregnation of the land and make a cake filter to limit the wall) and spoil disposal [2-3]. In Morocco, earth clays are mainly used for manufacturing traditional and modern construction materials (bricks, tiles, sanitary ...) and for pottery. The basic structure of layer silicates and all silicates is ion $\left(\mathrm{SiO}_{4}{ }^{4-}\right)$, where the silicon occupies tetrahedral sites. The aluminium ion $\left(\mathrm{Al}^{3+}\right)$ can substitute for $\mathrm{Si}^{4+}$, but it is generally located in the octahedral sheet.

\section{Materials and Methods}

\subsection{Bentonite of Trebia Material}

It is located on the western flank of Jebel Tidiennit. Its 
deposit is stratiform type affected by brittle tectonics. It appears as white to yellowish-white bentonites. reserves are estimated at 1,44 million tonnes.

Mineralogical analysis shows that bentonite Trebia is mainly composed of inorganic type beidelite montmorillonite (smectite) representing (63 wt $\%$ ), feldspar $(30 \%)$, magnetite represents $(5 \mathrm{wt} \%)$ and oxide of iron in the form of scales $(2 \mathrm{wt} \%)$, the cation exchange capacity is $89 \mathrm{meq} / 100 \mathrm{~g}$ and a specific surface area of $37 \mathrm{~m}^{2} / \mathrm{g}$, the chemical analysis shows a high percentage of silica, alumina and low $\mathrm{Na}_{2} \mathrm{O} \mathrm{K} \mathrm{K}_{2} \mathrm{O}$ (Table1).

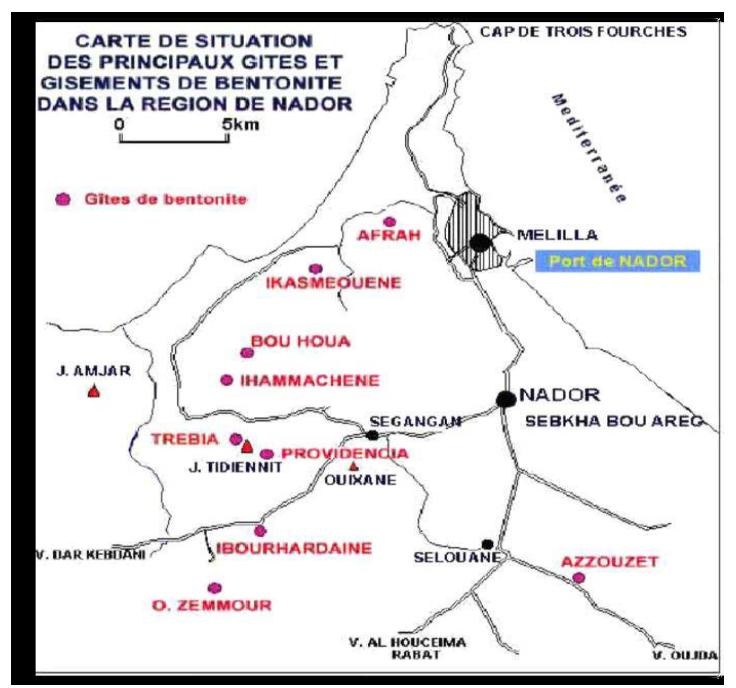

Figure 1. Location map of the city of White Bentonite of Trebia in Morocco.

\subsection{Methods}

The raw bentonite of Trebia and its fine fraction (less than

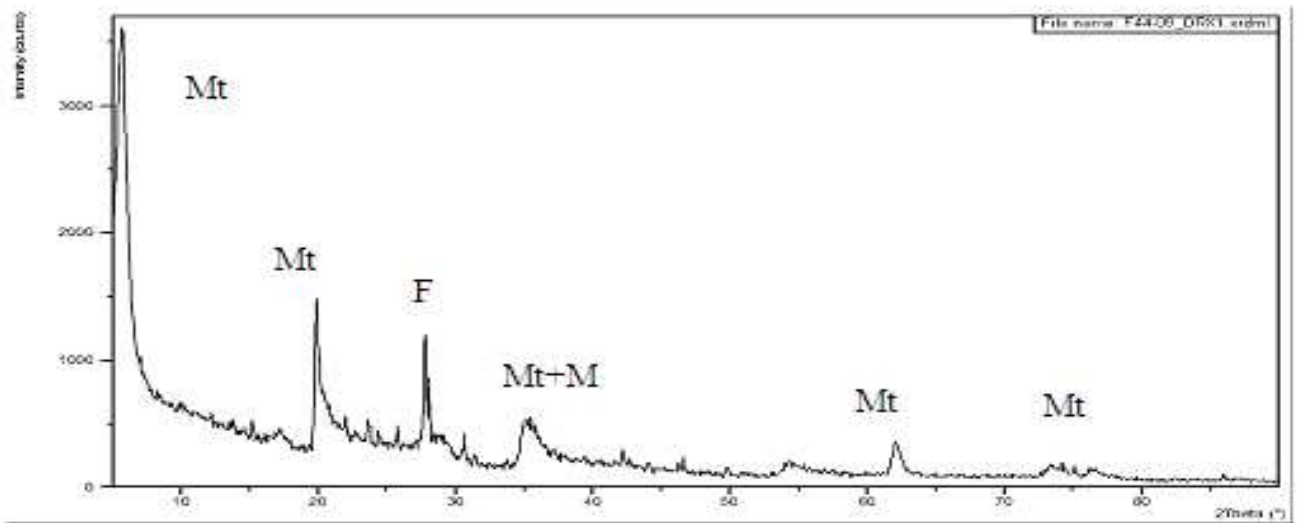

(Mt): montmorillonite, $(\mathrm{F})$ : feldspath, $(\mathrm{M})$ : magnetit.

Figure 2. RX diffractograms of bentonite of Trebia.

\subsection{Differential Thermal Analysis and Thermo Gravimetric Analysis}

A substance subject to heat treatment may change its physicochemical properties, such as a phase change, structural reorganization, decomposition, etc.[5]. Among the techniques used include differential thermal analysis (DTA), thermogravimetric analysis (TGA).
2 microns in diameter), which is isolated by sedimentation following the experimental procedure [4], were studied using X-ray diffraction (XRD), thermal analysis (DTA and TG), infrared spectroscopy (IR), X-ray fluorescence (XRF), scanning electron microscopy (SEM-EDX).

As the mineral composition is complex, it seemed necessary to characterize the clay by XRD analysis. Spectrometric analysis by SEM, SEM-EDX was performed at the Laboratory of Materials Chemistry IFM, University of Turin (Italy). This is a scanning electron microscope to detect chemical elements, XRD analysis was performed by a diffractometer $(45 \mathrm{kv}, 40 \mathrm{~mA}$ whose technical characteristics are: the thermograms were carried out by operating a XPERT-PRO inder the following conditions: heating rate $=$ $10^{\circ} \mathrm{C} / \mathrm{min}$, sample weight $=40 \mathrm{mg}$, atmosphere: air.

The Fourier transform infrared spectrometry (FTIR) were obtained on a spectrometer with a DTGS detector and a $\mathrm{KBr}$ beam splitter, the technique of pressed $\mathrm{KBr}$ disk (1 mg sample and $200 \mathrm{mg}$ of $\mathrm{KBr}$ ) was used, the spectra were recorded in the region of $4000-400 \mathrm{~cm}^{-1}$.

\section{Results and Discussion}

\subsection{X-Ray Analysis (XRD)}

\subsubsection{Treatise Contain Minerals}

The X-ray analysis diffractometric "Figure 2" of the white bentonite of Trebia shows that there is a majority phase (Montmorillonite, feldspar) and minority phases (magnetit, iron oxide) which identified by the database and the cards ASTM (American Society for Testing materials) which are justified by the characteristic peaks for the phyllosilicates. 
difference is related to the amount of heat released or absorbed by the material studied. And $\Delta \mathrm{T}$ is recorded as a function of temperature. This allows the detection of peak endothermic and exothermic changes.

\subsubsection{Thermo Gravimetric Analysis (TGA)}

The idea is to continuously monitor the change in mass of a sample as a function of temperature. The sample, placed in an alumina boat suspended from the beam of a balance, is located in a chamber at controlled temperature.

The equilibrium of the balance is provided by an electromagnetic compensation system. The change in mass, given by rebalancing the system, is recorded as a function of the temperature rise.

There are basically three endothermic peaks: the first between $95^{\circ}-100^{\circ} \mathrm{C}$ corresponding to the dehydroxylation of minerals bentonite of Trebia and a second at $530^{\circ} \mathrm{C}$ and the third at $720^{\circ} \mathrm{C}$ corresponding to the structural reorganization of the bentonite of Trebiaminerals. differential thermal analysis (TGA-DTA) is very useful, especially for groups of clay, the thermal analysis of bentonite of Trebia three steps, as shown in Figure 3, the first endothermic peak at $98^{\circ} \mathrm{C}$. We initially attributed to the departure of the water which is about $2 \mathrm{wt} \%$ bentonite of Trebia[6-7] The endothermic reaction that occurs in the range $110^{\circ} \mathrm{C}-630^{\circ} \mathrm{C}$ due to the gradual exit of water molecules associated with interlayer cations, the structure of water can be removed without destroying the network of clay. Both endo reactions in sequence in the range $500^{\circ}$ $\mathrm{C}-800^{\circ} \mathrm{C}$ are due to the departure of $\mathrm{OH}$ groups of structure (loss of $8 \%$ by weight). This suggests that in the range $630^{\circ}$ $\mathrm{C}-830^{\circ} \mathrm{C}$, as for the peak located around $710^{\circ} \mathrm{C}$, can be attributed to the amount of iron in octahedral sites [8].

the portion of the curve above $956^{\circ} \mathrm{C}$, reflecting the phase changes after the destruction of the structure of the bentonite of Trebia is quite variable. it appears for the first quartz $(\alpha)$ or $(\beta)$ and cristobalite, finally, the mullite.

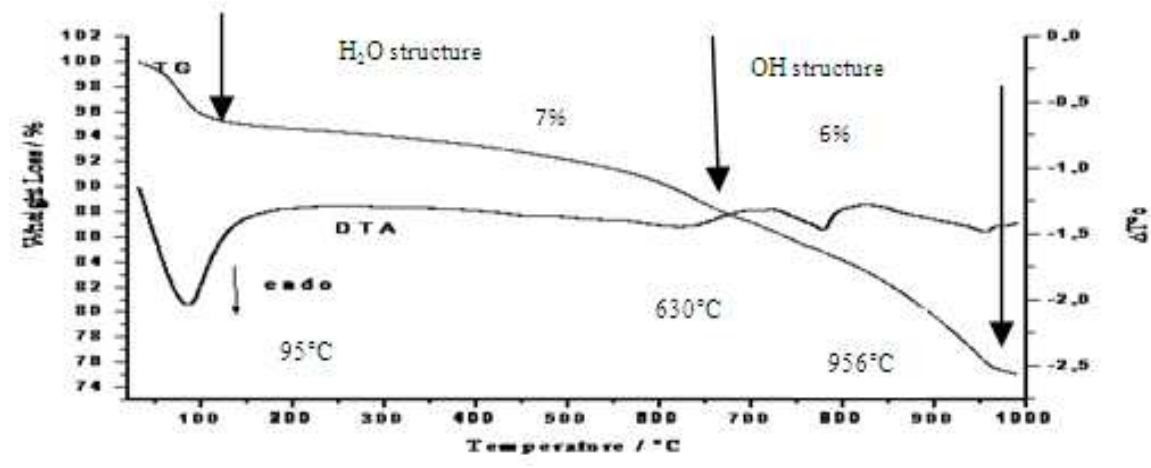

Figure 3. TG and DTA curves of white bentonite of Trebia.

\subsection{Fourier Transform Infrared Spectroscopy (FTIR)}

From Figure 4, there is an absorption band at $3646 \mathrm{~cm}^{-1}$ corresponds to stretching vibration of the $\mathrm{OH}$ group chemically adsorbed on clays. Another band around 3383 $\mathrm{cm}^{-1}$ corresponds to stretching vibration $v\left(\mathrm{H}_{2} \mathrm{O}\right)$. This is mostly from physical absorption of water between the bentonite of Trebia layers. a band corresponding to the bending vibration $\delta\left(\mathrm{H}_{2} \mathrm{O}\right)$ of the physical sorption of water observed around $1643 \mathrm{~cm}^{-1}$, there is also a band corresponding to stretching vibration of $\mathrm{Si}-\mathrm{O}$ band observed around 1032-1210 $\mathrm{cm}^{-1}$ group tetrahedron $\left(\mathrm{SiO}_{4}\right)$. The band observed around $3430-1430 \mathrm{~cm}^{-1}$ is due calcium carbonate. The bands observed around $520 \mathrm{~cm}^{-1}$ and $470 \mathrm{~cm}^{-1}$ are due to bending vibration of $\mathrm{Al}-\mathrm{O}-\mathrm{Si}$ and $\mathrm{Si}-\mathrm{O}-\mathrm{Si}$, respectively. Vibration bands observed at 920,880 and $841 \mathrm{~cm}^{-1}$ correspond to $\mathrm{AlAlOH}$, and $\mathrm{AlFeOH} \mathrm{AlMgOH}$ respectively [9-10-11].

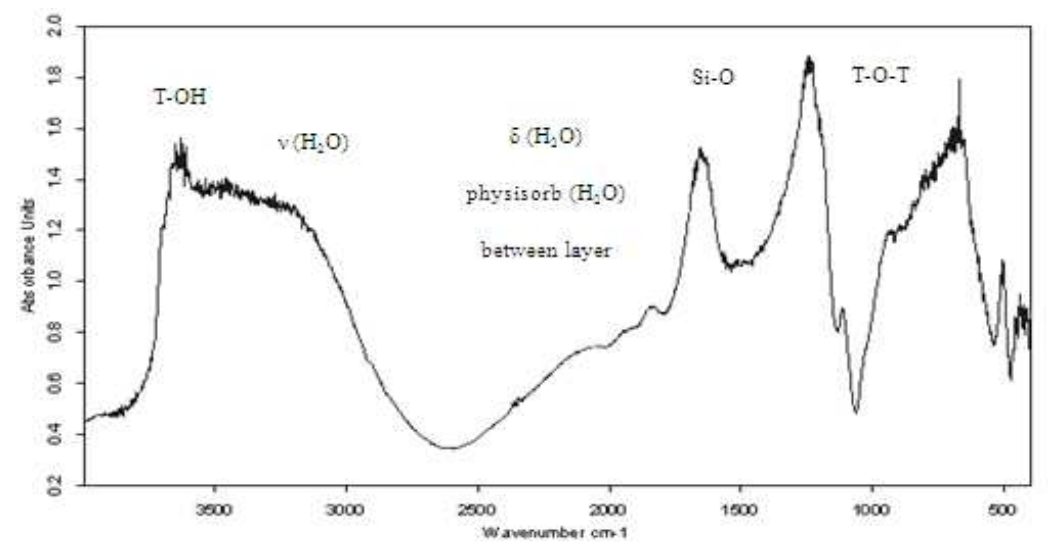

Figure 4. FTIR white bentonite of Trebia. 


\subsection{Elemental chemical analysis Scanning Electronic Microscope (SEM) Interpretation}

The elemental chemical analysis of the white bentonite of Trebia (Table 1) shows that there is a significant percentage of $\mathrm{SiO}_{2}(58,55 \%)$ of $\mathrm{Al}_{2} \mathrm{O}_{3}(26,89 \%), \mathrm{Na}_{2} \mathrm{O}(2,05 \%)$ and $\mathrm{K}_{2} \mathrm{O}(0,42 \%)$ and a small percentage of $\mathrm{TiO}_{2}(0,15)$. The morphology shows an irregularity of the particles forming the aggregate of clay.

Table 1. Characterization by Fluorescence X of white bentonite of Trebia.

\begin{tabular}{|c|c|c|c|c|c|c|c|}
\hline compounds & $\mathrm{SiO}_{2}$ & $\mathrm{Al}_{2} \mathrm{O}_{3}$ & $\mathrm{~K}_{2} \mathrm{O}$ & $\mathrm{CaO}$ & MgO & $\mathrm{TiO}_{2}$ & $\mathrm{Na}_{2} \mathrm{O}$ \\
\hline$w t \%$ & 58,55 & 26,89 & 0,42 & 0,82 & 2,01 & 0,15 & 2,01 \\
\hline
\end{tabular}

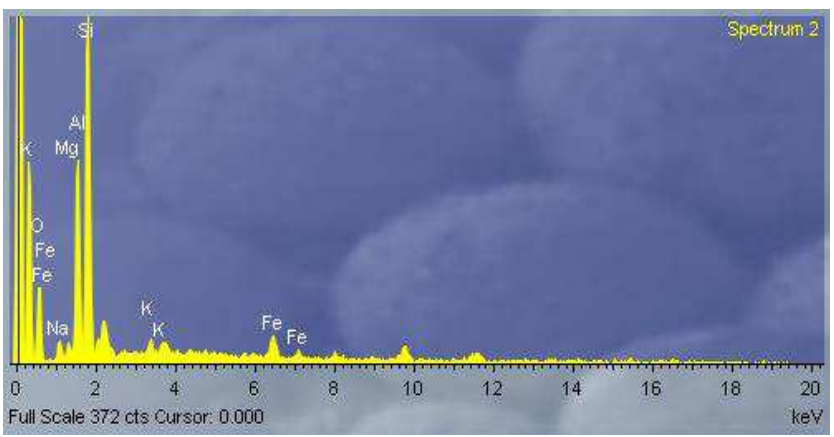

(a)

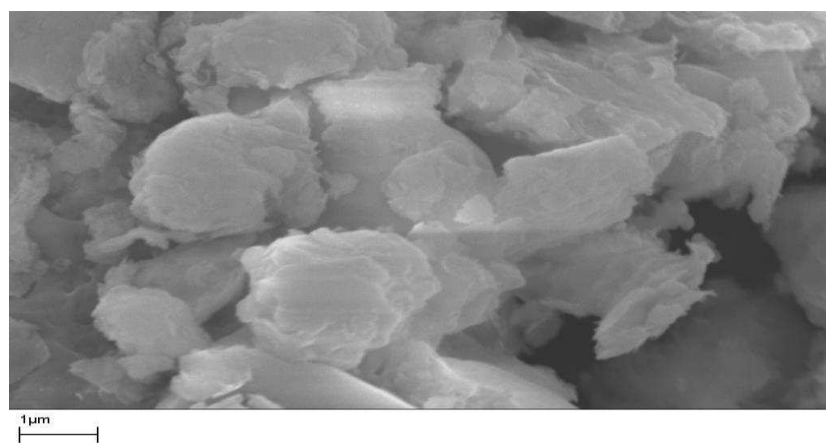

(b)

Figure 5. SEM ((a) EDS and (b) morphology) of white bentonite of Trebia

The Figure 5.(a) shows the energy spectra of the element present in the sample corresponding to the chemical analysis of the scanning electron microscopy (SEM), (b) the morphology showed irregularity fine micrometer particle forming the aggregate of the sample.

\subsubsection{Weight Loss (LOI)}

The decrease in the weight of the material from drying at $110^{\circ} \mathrm{C}$ and the firing temperature to $1000^{\circ} \mathrm{C}$ is determined using the following formula:

$$
\text { Weight loss } \%=100\left(\mathrm{~m}_{110}-\mathrm{m}_{1000}\right) / \mathrm{m}_{110} .
$$

$\mathrm{m}_{110}$ with the mass of the material at $110^{\circ} \mathrm{C}$ and $\mathrm{m}_{1000}$ mass of the sample fired at $1000^{\circ} \mathrm{C}$ temperature.

The weight loss can only know the amount of products that may decompose or evaporate during cooking. At $500^{\circ} \mathrm{C}$, the product loses its water content. Between 700 and $900^{\circ} \mathrm{C}$, the following reactions may occur [12]:
*Oxidation of $\mathrm{FeO}$ :

$$
\mathrm{FeO} \rightarrow \mathrm{Fe}_{2} \mathrm{O}_{3}
$$

* Decomposition of carbonates:

$$
\mathrm{CaCO}_{3} \rightarrow \mathrm{CaO}+\mathrm{CO}_{2}
$$

\subsection{Study of the White Bentonite of Trebia of Nador}

\subsubsection{Humidity}

The evolution in the weight of the material between the initial state and drying at $110{ }^{\circ} \mathrm{C}$ is determined using the following formula:

$$
\text { Humidity } \%=100\left(\mathrm{~m}_{\mathrm{i}}-\mathrm{m}_{110}\right) / \mathrm{m}_{\mathrm{i}}
$$

with $\mathrm{m}_{\mathrm{i}}$ the mass of material in the initial state and $\mathrm{m}_{110}$ mass of matter at $110^{\circ} \mathrm{C}$.

\subsubsection{Linear Shrinkage during Drying}

Determining the shrinkage value is by studying the variation of the average lengths of lines recorded on the briquettes between wet and drying at $110 \circ \mathrm{C}$. The following formula allows the calculation of drying shrinkage:

Linear shrinkage on drying

$$
(\%)=\left(\mathrm{Lw}-\mathrm{L}_{110} / \mathrm{Lw}\right) \times 100
$$

with the length wet $\mathrm{Lw}$, the length drying at $110^{\circ} \mathrm{C}\left(\mathrm{L}_{110}\right)$.

\subsubsection{Withdrawal of Cooking}

Determining the shrinkage value is by studying the variation of the average lengths of lines recorded on the briquettes from the drying at $110 \circ$

$\mathrm{C}$ and firing at $1000^{\circ} \mathrm{C}$. The following formula allows calculation of the withdrawal to cook:

Withdrawal of cooking $(\%)=\left(\mathrm{L}_{110}-\mathrm{L}_{1000} / \mathrm{L}_{110}\right) \times 100$,

$\mathrm{L}_{1000}$ length with cooking, the length $\mathrm{L}_{110}$ drying at $110^{\circ}$ C.

\subsubsection{Water Absorption Capacity (WAC) (\%)}

This test is the ratio of the difference between the dry weight after absorption and dry weight cooked, the formula allows the calculation of the absorption capacity of water:

$$
\% \text { absorption }=\left(\mathrm{W}_{\text {dry }}-\mathrm{W}_{\text {cocked }} / \mathrm{W}_{\text {cocked }}\right) \times 100
$$

with $\mathrm{W}_{\text {dry }}$ abs dry weight after absorption and $\mathrm{W}_{\text {cocked }}$ dry 
weight cooked.

\subsubsection{The Plasticity Index (PI)}

This test is the ratio of water weight and the weight of dry matter, the formula allows the calculation of the plasticity index (PI):

$$
\text { Plasticity index } \%=\left(\mathrm{W}_{\mathrm{w}} / \mathrm{W}_{\mathrm{dm}}\right) \times 100
$$

with $\mathrm{W}_{\mathrm{w}}$ the weight of water and $\mathrm{W}_{\mathrm{dm}}$ weight dry matter.

\subsubsection{Mechanical Resistance to Flexion (RMF)}

The determination of the resistance in $\mathrm{kg} \times \mathrm{f} / \mathrm{cm}^{2}$ that can develop the bar against bending under the effect of a load on the bar, is given by the following formula:

$$
\mathrm{R}\left(\mathrm{kg} / \mathrm{cm}^{2}\right)=\mathrm{P} \times 3 \times \mathrm{d} / 2 \times \mathrm{w} \times \mathrm{e}^{2}
$$

$\mathrm{R}$ with the mechanical resistance to bending, the force in $\mathrm{kg} P$ that causes the breakdown of the bar $(60 \mathrm{~kg})$, d distance between two supports of the unit $(120 \mathrm{~mm})$, w the width of the strip $(20 \mathrm{~mm})$, e the thickness of the bar $(10 \mathrm{~mm})$.

\section{Interpretation}

The white bentonite of Trebia has a medium heat loss, low shrinkage, good flexural strength and good behavior in plasticity (Table 2). In a slurry composed of $320 \mathrm{~g}$ bentonite of Trebia and $300 \mathrm{ml}$ of water was added gradually increasing amounts of deflocculant (sodium carbonate) to each dosage, was allowed to stir for $20 \mathrm{~min}$ and then measured the viscosity of the slip. The result of this study is shown in figure 6 . In this study, it was found that from $0,42 \%$ of deflocculation, the viscosity is minimum and stable. This suggests that, for the white bentonite of Trebia has a flowability optimal deflocculant of $0,42 \%$ sodium carbonate $\left(\mathrm{Na}_{2} \mathrm{CO}_{3}\right)$.

Table 2. Technological characteristics of white bentonite of Trebia.

\begin{tabular}{ll}
\hline Characteristic & Result \\
\hline - Humidity (H) (\%) & 10,19 \\
- Loss on ignition (PF) (\%) & 11,08 \\
- Linear shrinkage during drying (RL) (\%) & 2,15 \\
- Total shrinkage during cooking (RT) (\%) & 11,07 \\
- Water absorption capacity (WAC) (\%) & 34,01 \\
- The plasticity index (PI) (\%) & 23 \\
- Mechanical resistance to flexion (RMF) (kg/cm $)$ & 99 \\
\hline
\end{tabular}

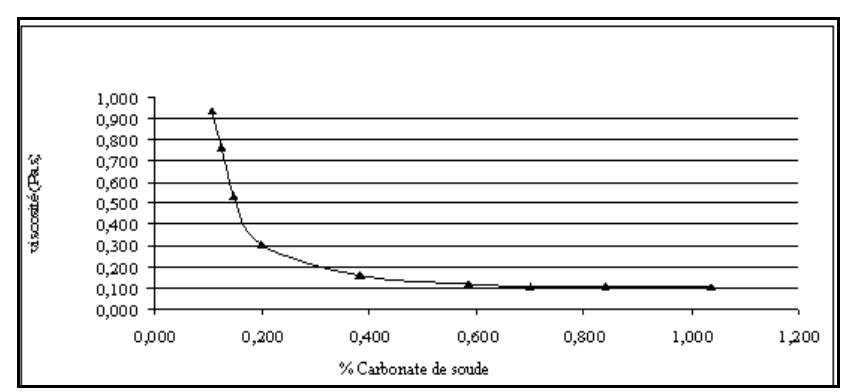

Figure 6. Deflocculation of white Bentonite of Trebia with Sodium carbonate $\left(\mathrm{Na}_{2} \mathrm{CO}_{3}\right)$.

\begin{tabular}{|c|c|c|c|c|c|c|}
\hline \multirow{2}{*}{ Formula (\%) } & \multicolumn{4}{|l|}{ Materiel } & \multirow{2}{*}{$\begin{array}{l}\text { Result (\% loss of } \\
\text { ignition) }\end{array}$} & \multirow{2}{*}{ prepared slurry } \\
\hline & ${ }^{1}$ white bentonite & ${ }^{2}$ chamotte & ${ }^{3}$ feldspar & ${ }^{4}$ quartz & & \\
\hline Formula 1 & 14,00 & 66,00 & 8,00 & 12,00 & 7,75 & Good \\
\hline Formula 2 & 10,00 & 70,00 & 8,00 & 12,00 & 7,69 & Good \\
\hline Formula 3 & 08,00 & 72,00 & 8,00 & 12,00 & $*$ & Poor \\
\hline
\end{tabular}

Table 3. Preparation of slurry with different formulations $(08,10$ and $14 \%)$.

* not determined

1 : white bentonite Trebia. 2 : commercial chamotte 3 : commercial feldspar 4 : commercial quartz

\section{Conclusion}

From the results we can say that the white bentonite of Trebia has the same characteristics of clays used in the ceramics industry (medium heat loss, low shrinkage, good flexural strength and good behavior in plasticity). For this white bentonite of Trebia adding $0,42 \%$ sodium carbonate (Figure 6) is sufficient to have a good deflocculation and the viscosity is minimum corresponds to the stability of the slip, in his introduction to a formula of slip was successful with a rate of 10 to $14 \%$ (formula $1-2$, Table 3 ). The white bentonite of Trebia has an average loss on ignition is due to the elimination of the water content, the decomposition of certain minerals such as carbonates and associated with the combustion of organic matter in association with minerals such as micas, feldspars or carbonates, the temperature of appearance of a liquid phase during sintering is reduced. The levels of iron oxide and titanium influence the color of ceramic shards. As for organic matter, they affect the rheology of suspensions and behavior of matter at the formatting.

The X-ray diffraction patterns allowed us to identify the different minerals that make up the white bentonite of Trebia, compared with the available data, we identified montmorillonite and feldspar as bentonite of Trebia minerals, other minerals present as impurities major are magnetit and iron oxide.

We can conclude that these results show the important features to justify its use in the ceramic industry.

\section{Acknowledgements}

My sincere thanks go to Pr.Salvatore Goluccia, Dr.Gesley and laboratory IFM staff of the University of Turin (Italy), for helpful advice the study of different samples of Moroccan clay. 


\section{References}

[1] S.Laribi, J.-M. Fleureau, J.-L. Grossiord and N.Kbir-Ariguib, "Comparative yield stress determination for pure and interstratified smectite clays" Rheol. Acta 44, 262-269 (2005).

[2] A.Besq, " Ecoulements laminaires de suspension de bentonite industrielles. Caractérisation rhéométrique Ecoulements en conduites axisymétriques. Applications aux activités du Génie Civil," Thèse de doctorat de l'Université de Poitiers (2000)

[3] N.Jozja,"étude de matériaux argileux Albanais. Caractérisation "multi-échelle" d'une bentonite magnésienne. Impact de l'interaction avec le nitrate de plomb sur la perméabilité." Thèse de doctorat de l'Université d'Orléans (2003).

[4] A. Alami, Boulmane, M., Hajjaji, M., Kacim, S., 1998. Chemico-mineralogical study of a Moroccan clay. Ann. Chem. Sci. Master.23,173 -176.

[6] RC.Mackenzie, Caillére, s. 1975 thermal characteristics of soil minerals, In : gieseking, J.E (Ed), soil components vol.2.springer-verlag, new york, pp.529-571.

[7] N.D.,Todor, 1976. Thermal analysis of minerals. Abacus pren, kent, UK, $256 \mathrm{pp}$.

[8] A.Mathieu-Sicaud, and J. Mering, "Etude au microscope de la montmorillonite et de l'hectorite saturées par différents cations" Bull. Soc. Franc. Miner. Crist. 74, 439-455 (1951).

[9] Farmer, V.C. , 1974. The layer silicates. In :Farmer, V.C.(Ed), the infraredspectra of minerals.Monograph, vol.4.The mineralogical society, london, pp.331-363.

[10] J.Madejova, P.Komadel, B.Cicel, 1994. Infrared study of octaedral site population in smectites. Clay Minerals 29,319-326.

[11] J.Madejova, FTIR technique in clay mineral studies, Vib. Spectrosc.31 (2003) 1-10.

[12] P. Lefort, Analyse élémentaire d'une argile, ENSCI, Limoges, France, 1988, pp. 11-12.

[5] C.Jouenne A.; Traité de céramiques et matériaux minéraux ; Ed. Septima, (1990). 